\title{
Journal of Diabetes Research and Therapy
}

\section{Discovering the Right Time to Take Food to Smash Diabetes}

\section{Akbar Nikkhah*}

Department of Animal Sciences, Faculty of Agricultural Sciences, University of Zanjan, National Elite Foundation, Iran

Corresponding author: Akbar Nikkhah, Department of Animal Sciences, Faculty of Agricultural Sciences, University of Zanjan, National Elite Foundation, Iran, E-mail: anikkha@yahoo.com; nikkhah@znu.ac.ir

This public policy article establishes circadian time of nutrient consumption as a working science to feasibly prevent and manage diabetes. Conventionally, almost all scientific efforts have focused on managing daily quantity and quality of nutrient intake in programming public nutrition and health. However, a very significant applied science, incrementally emerging recently, is timing of eating different nutrients over the 24 -h period.

The science of eating timing stems from the principle that the circadian evolutionary nature of human life has led to development of almost 24-h rhythms in cell physiology and function [1-3]. As a result, metabolism extent and rate differ substantively during different hours of the 24-h period that are also independent from food intake per se [4-6]. Eating as a biological synchronizer of cell metabolism is highly integrated with the time when it occurs in regulating biochemical reactions $[7,8]$. This means that eating the same amount of the same food at different hours of the 24-h period has different metabolic and health consequences. In other words, cell metabolism and waste management efficiency and thus sensitivity to pathological conditions and agents depend highly on when during 24-h period (i.e., early to late morning, noon, mid to late afternoon, evening, overnight) nutrients are taken.

Basically, human glucose intolerance and insulin insensitivity develop as day leaves for night $[4,9]$. This phenomenon provides an evolutionary proof for the circadian nature of human activity and resting time that keeps the body and its differential cells well-prepared for varying functions [10]. Endocrinologically, resting can occur most desirably when the gastrointestinal system and interrelated splanchnic and peripheral tissues are not overly involved in nutrient bioprocessing and energetic. Owing to such reduced energy demands at times of limited activity during evening and later overnight, the body has not learnt to require insulin and other facilitating hormones and proteins to assimilate nutrients. As such, any overflow of glucose and energy-producing nutrients later in evening and overnight would oppose human evolution in healthy management of cell physiology.

The public education programs must increasingly communicate the significance of timing of food intake as an emerging public science in improving human health and welfare. Eating energizing foods during day especially early morning must be encouraged. On the other hand, taking large and concentrated meals overnight must be discouraged and minimized $[8,10]$. Healthy eating behavior demands taking frequent but rather small meals during day and avoiding a large single evening meal. This is the lesson that evolution teaches humans [11]. Such guidelines must be expanded and specified for different age groups, physiological states, work conditions, and other relevant divisions according to research findings and be included in future public recommendations. The current dietary references of intake do not have such information yet [12].
In a nutshell, the increasing rates of diabetes and related metabolic complexities with the modernizing trends of human life necessitate developing feasible and simple approaches of prevention and treatment. When to eat will be an ultimate frontier to accomplishing such a global triumph. However, despite its simplicity, effective timing of eating requires diligent and hard efforts to make it a workable daily routine alongside a well-disciplined exercise program.

\section{Acknowledgments}

The Ministry of Science Research and Technology, National Elite Foundation, and University of Zanjan, Iran, are gratefully acknowledged for supporting the author's global programs of optimizing science edification in the third millennium.

\section{References}

1. Nikkhah A (2011) Bioscience of ruminant intake evolution: feeding time models. Adv Biosci Biotechnol 2: 271-274.

2. Nikkhah A (2012) Time of Feeding an Evolutionary Science, Lap Lambert Publishing, GmbH \& Co. KG, Germany.

3. Nikkhah A (2014) Eating timing and diabetes. Int J Diabetol Vas Dis Res 2: 101.

4. la Fleur SE, Kalsbeek A, Wortel J, Fekkes MI, Buijs RM (2001) A daily rhythm in glucose tolerance: a role for the suprachiasmatic nucleus. Diabetes 50: 1237-1243.

5. Nikkhah A (2015) Intake circadian physiology: An overlooked public health concern. Endocrinol Metab Synd 1:1.

6. Nikkhah A (2014) Perspective: Nutrient intake chronophysiology: A rising public health concern. J Nutr Therap 3 (4): 156-157.

7. Nikkhah A (2015) Untimely intake as a postmodern public health bioterrorism. J J Bioterror Biodef 7: e118.

8. Nikkhah A (2015) Avoid large night meals to stay fit. J Obes Weight Loss Ther 4: e115.

9. Nikkhah A (2015) Optimizing health management through circadian feed intake rhythms: A prognostic SciTech. J Vet Sci Technol 6: e115.

10. Nikkhah A (2014) When to eat to beat obesity and diabetes? Journal of Diabetes and Metabolism 5: e115.

11. Nikkhah A (2014) Timing of eating a global orchestrator of biological rhythms: dairy cow nitrogen metabolism and milk fatty acids. Biol Rhythms Res 45 (5): 661-670.

12. Dietary Reference Intakes (DRI) (2007) Recommended Intakes for Individuals, Food and Nutrition Board, Institute of Medicine, National Academies. National Academy of Sciences, Washington, D.C. USA. 